\title{
Systematik des Gesamtkommentars
}

(Stand: Oktober 2020)

Band I: Zivilverfahren I

I.1 Brüssel Ia-VO

I.2 Brüssel I EU-DK Abk

I.3 LugÜbk 2007

Band II: Zivilverfahren II - Insolvenz
A. Zuständigkeit, Anerkennung, Vollstreckung
II.1 EG-VollstrTitelVO
II.2 EG-MahnVO
II.3 EU-BagatellVO
II.4 EU-KpfVO
II.5 HProrogÜbk 2005
II.6 HUrtÜbk
B. Rechtshilfe
II.7 EG-ZustellVO 2007
II.8 Zust EU-DK Abk
II.9 EG-BewVO
C. Insolvenz
II.10 EuInsVO

Band III: Internationales Schuldrecht

III.1 Rom I-VO

III.2 Rom II-VO

Band IV: Ehescheidung - Güterrecht
A. Ehescheidung
IV.1 Brüssel IIb-VO
IV.2 Rom III-VO

B. Güterrecht

IV.3 EU-EheGüterVO

IV.4 EU-LP-GüterVO

Band V: Sonstiges FamR - Erbrecht
A. Unterhalt
V.1 EG-UntVO
V.2 HUntVerfÜbk 2007

B. Kindes- und Erwachsenenschutz

V.3 HUntStProt 2007

V.4 KSÜ

V.5 ErwSÜ

V.6 EU-SchutzMVO

C. Erbrecht

V.7 EU-ErbVO 
